\title{
Influence of fixation conditions on the performance of glutaraldehyde-treated porcine aortic valves: towards a more scientific basis
}

\author{
NEIL D BROOM AND FERGUS J THOMSON \\ From the Department of Mechanical Engineering, University of Auckland, New Zealand
}

\begin{abstract}
To maintain optimum mechanical properties in glutaraldehyde-treated heart-valve tissue the full collagen crimp geometry originally present in the relaxed fresh tissue should be retained. By varying the pressure at which glutaraldehyde fixation is carried out, considerable alterations to this crimp geometry can be achieved. The mechanical stiffness of the preserved tissue is consequently affected, and this in turn has a striking influence on both the opening behaviour of the valve and the degree of strain localisation in the leaflet tissue.

A pressure of $100 \mathrm{mmHg}$ eliminated the collagen crimp geometry entirely, and this resulted in the formation of sites of local strain or kinks in the valve leaflets during opening. It is expected that this strain localisation phenomenon will influence the long-term fatigue durability of the treated tissue. Pressures even as low as $4 \mathrm{mmHg}$ result in significant reductions of crimp geometry.

Fresh valves should therefore be fixed under a positive head of pressure sufficient only to ensure that the leaflets seal along their coapting free margins. A pressure of less than $1 \mathrm{mmHg}$ was sufficient to achieve this.

Leaflets of the commercially available Hancock valve show features similar to valves fixed in glutaraldehyde at about $100 \mathrm{mmHg}$ pressure.
\end{abstract}

The glutaraldehyde-preserved porcine aortic valve has in recent years been widely used as a bioprosthesis in valve replacement surgery. Successful mediumterm trial periods have been reported (for instance, Albert et al (1977) - 4 years; and Stinson et al (1977) -4.4 years).

How long will these treated valves last? Over the trial periods currently achieved there are few reports (Brown et al, 1978; Rose et al, 1978) of serious degradation of the valvar tissue and in particular the leaflets which sustain most of the repeated haemodynamic loading. General concern is, however, expressed in published reports that nothing is known about the long-term durability of the treated tissue. Clearly what is required is some understanding of the mechanisms relating to tissue breakdown after extended function so that valves prematurely retrieved can be assessed scientifically for early signs of tissue deterioration.

The manufacturers of these bioprostheses provide few specific details of the conditions of fixation, and the question arises whether commercially available valves have been optimally treated both for immediate function and long-term tissue durability.

With respect to the first of these difficulties Broom $(1977,1978 \mathrm{a})$ has recently investigated the fatigue behaviour of glutaraldehyde-treated mitral heartvalve tissue. He showed that after extended cyclic loading of the tissue serious disruption of the collagenous array occurs. The probable mechanisms leading to this tissue disruption were also investigated.

Concerning the second problem-namely defining the optimum conditions of fixation-Broom (1978b) also showed that the final mechanical properties of glutaraldehyde-treated porcine aortic leaflet tissue are dependent on the condition of the collagen waveform or crimp at fixation. His results indicated that the functional behaviour of the glutaraldehydepreserved valve is dependent on the hydrostatic head of pressure applied to the valve during its fixation.

In this presentation the structural differences and associated mechanical characteristics in porcine 
aortic leaflets resulting from fixation in glutaraldehyde under varying amounts of hydrostatic pressure are examined and related both to immediate function and to predictions of long-term durability and failure modes.

\section{Experimental methods}

\section{VALVE FIXATION}

Aortic valves were trimmed from freshly dissected porcine hearts. The valves were then checked for competence by attaching each to a length of flexible plastic tubing and applying a hydrostatic head of pressure. Fixation was accomplished by filling this tube with $0.625 \%$ glutaraldehyde (in $0.15 \mathrm{M}$ phosphate buffer at $\mathrm{pH} 7 \cdot 2$ ). Fixation pressures of 4 and $100 \mathrm{mmHg}$ were achieved by varying the height of the tube with respect to the valve. A third fixation pressure was obtained by immersing the valve in the fixation solution and then raising the attached aorta slightly above the solution level until the leaflets closed. With this technique it was estimated that the pressure in the valve was less than $1 \mathrm{mmHg}$ and it is henceforth denoted by " 0 " $\mathrm{mmHg}$ pressure. A total of 14 valves were examined; five at $100 \mathrm{mmHg}$, four at $4 \mathrm{mmHg}$, and five at " 0 " $\mathrm{mmHg}$.

All valves were fixed for one hour at the predetermined pressure and then immersed overnight at zero pressure to ensure that the fixative penetrated the bulkier parts of the valve tissue.

\section{VALVE FUNCTION STUDIES}

The functional behaviour of the glutaraldehydetreated valves was investigated using a pulsatile flow tunnel described earlier by Thomson (1976). The valves were mounted in plastic encasements using a castable alginate dental impression material poured into the space between the irregular outer surface of the valve and the encasement. The mounted valves could then be secured firmly in the observation cell of the flow tunnel and photographed in the axial direction under different flow conditions. Since the valves were not mounted on stents for this series of experiments measurements could be made only under steady forward flow conditions. The pressure drop across the open valve was measured as a function of volume flow rate using a differential pressure transducer. All valves were tested in Ringer's solution at about $20^{\circ} \mathrm{C}$.

\section{EXAMINATION OF LEAFLET PROPERTIES}

After the flow studies the leaflets were subjected to a simple probe indentation test on their convex ventricular surfaces. The appearance of the indentation was related qualitatively to the mechanical properties of the fixed tissue. The leaflets were then excised and examined in their wet functional condition using Nomarski interference contrast, thus enabling the collagen and elastin structures to be viewed directly (Broom, 1978c).

Pieces of the leaflets about $2 \mathrm{~mm}$ wide and cut in the long circumferential direction of the leaflet belly were then prepared. Mechanical stress/strain $(\sigma / \epsilon)$ measurements were conducted on these test specimens using a microtensile straining device that is attached directly to the stage of an optical microscope fitted with Nomarski contrast. Broom (1978b) has recently described the design and working of the straining device.

\section{COMPARATIVE STUDY OF COMMERCIAL}

HETEROGRAFT VALVE

A single Hancock valve (Model $342 \mathrm{~A}-\mathrm{V}$, Ser No M31852) was also examined with respect to leaflet opening behaviour, structure, and mechanical $\sigma / \epsilon$ behaviour. This extends the earlier studies reported by Thomson and Barratt-Boyes (1977).

\section{Experimental results}

\section{OBSERVATION OF LEAFLET MOVEMENT}

Sequential photographs of leaflet movement for flow rates in the range 0 to $10 \mathrm{l} / \mathrm{min}$ are shown for valves treated at " 0 ", 4 , and $100 \mathrm{mmHg}$ in figs 1 to 3 . Figure 5 shows a similar sequence for the Hancock valve. In view of the size variations between the variously treated valves with consequential flow velocity differences, no attempt was made to compare behaviour of each valve at identical flow rates.

\section{Valves fixed at $100 \mathrm{mmHg}$}

The response of the leaflets was generally sequential rather than simultaneous (fig $1 \mathrm{a}-\mathrm{h}$ ).

There were two distinct types of leaflet movement in the opening function of these high pressure treated valves.

(1) Progressive opening, the associated leaflet strains being accommodated at specific sites on the leaflet free edge. The leaflet free edge assumed a distinctive appearance comprising a combination of angular kinks and near-linear sections (indicated by arrows (fig 1c).

(2) Virtually no leaflet movement (that is, the closed position was maintained) until a significant flow rate was reached, and then gross movement in which the leaflet was largely swept aside. This second type of movement usually included a localised hinging action in the leaflet near its margin of attachment along the aortic wall (see leaflet 1 in fig 1e,f). The behaviour of leaflet 2 in fig 1 represents a combination of both mechanisms: a gross hinge 



Fig 1 Axial views of $100 \mathrm{mmHg}$ valve for a range of steady forward flow rates in l/min as follows: $(a) 0 \cdot 0$, (b) $0 \cdot 3,(c) 1 \cdot 2,(d) 2 \cdot 3,(e) 3 \cdot 3,(f) 5 \cdot 0,(g) 6 \cdot 9,(h) 9 \cdot 1$. Leaflet numbers are indicated in fig la. Leaflet 1 remained almost fully closed up to a flow rate of $3.3 \mathrm{l} / \mathrm{min}$ and then opened completely in a single movement at some flow rate less than $5 \mathrm{l} / \mathrm{min}$. Leaflet 2 was closed up to $2.3 \mathrm{l} / \mathrm{min}$ and then partially opened in a single movement by $3.3 \mathrm{l} / \mathrm{min}$. Further opening was progressive with increasing flow rate beyond $3.3 \mathrm{l} / \mathrm{min}$. Leaflet 3 opened progressively from onset of flow reaching its fully open position by $2 \cdot 3 \mathrm{l} / \mathrm{min}$.

movement (fig 1e, f) followed by further leaflet opening via kink formation (fig $1 \mathrm{f}-\mathrm{h}$ ).

Valves fixed at " 0 " $\mathrm{mmHg}$

The valves fixed at almost zero pressure ("0" $\mathrm{mmHg}$ ) exhibited a gradual, nearly simultaneous movement of all three leaflets from the onset of flow (fig $2 a-h)$.
There was no evidence of kink formation at the free edges of any leaflet but rather a constantly moving curvilinear profile. The progressive opening response of the leaflets implied that no single region of the leaflet acted as a preferred "hinge" site, but instead deformation spread across the entire leaflet as the flow rate increased.
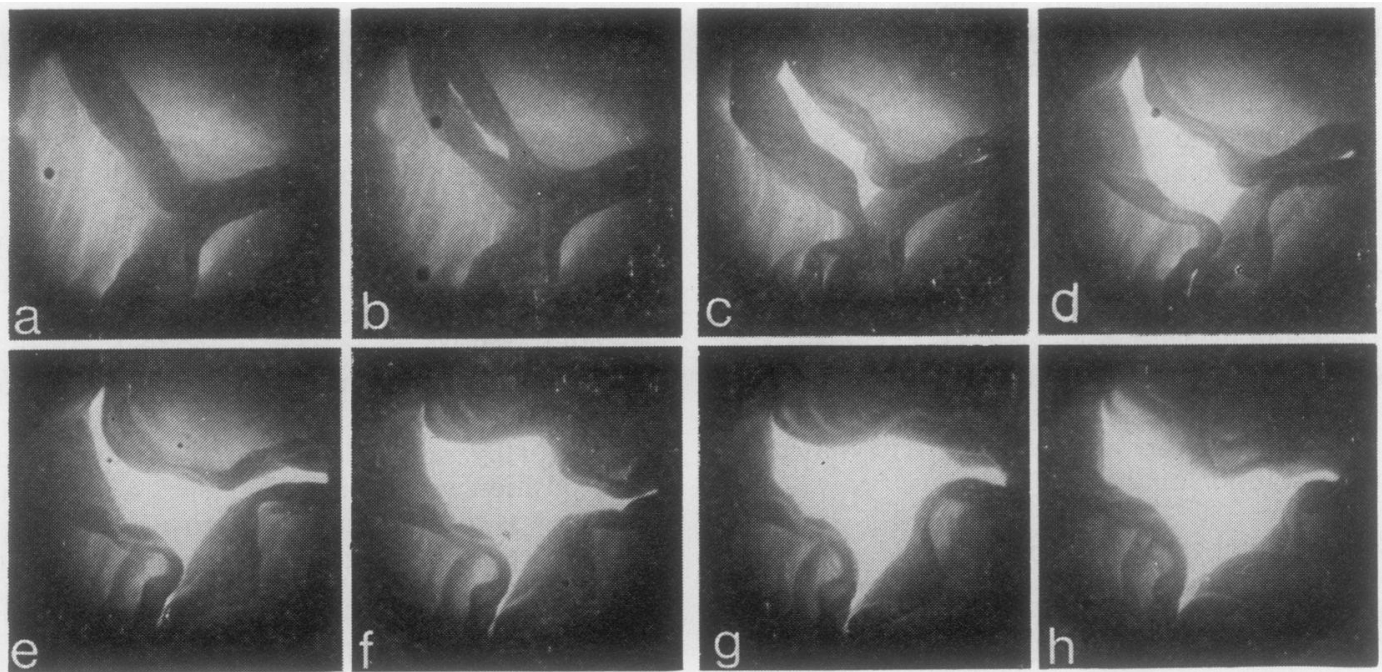

Fig 2 Axial views of " 0 " $\mathrm{mmHg}$ valve for a range of steady forward flow rates in $1 /$ min as follows: (a) $0 \cdot 0$,

(b) $0 \cdot 1,(c) 0 \cdot 6,(d) 1 \cdot 2,(e) 2 \cdot 0,(f) 3 \cdot 0,(g) 4 \cdot 7,(h) 6 \cdot 5$. All leaflets opened progressively from onset of flow. 
Valves fixed at $4 \mathrm{mmHg}$

Valves fixed at $4 \mathrm{mmHg}$ showed leaflet behaviour intermediate between that of the 100 and " 0 " $\mathrm{mmHg}$ valves (fig 3a-h). The leaflet free edges of the valve depicted in fig 3 maintained the curvilinear form characteristic of valves fixed at "zero" pressure (fig 2). This was not always true of valves fixed at $4 \mathrm{mmHg}$ however, and fig $4 \mathrm{a}-\mathrm{d}$ provides evidence that the "kink" mode of leaflet movement also occurred at this fixation pressure. While the kinks observed in this $4 \mathrm{mmHg}$ valve did not form such sharp apices as those observed in the $100 \mathrm{mmHg}$ valves (compare fig $4 \mathrm{c}$ and fig 1c) their presence in some $4 \mathrm{mmHg}$ valves indicated that localised deformation tended to occur in valve leaflets fixed even at this relatively low pressure.

\section{Hancock valve}

The opening behaviour of the single Hancock valve tested during the present experiments resembled that of the valves fixed at $100 \mathrm{mmHg}$ pressure (fig $5 \mathrm{a}-\mathrm{h}$ ). Clearly visible kinks are marked with arrows in fig 5 e.

\section{FLOW RATE AND PRESSURE LOSS STUDIES}

It was expected that the forward flow pressure drop measurements would enable the flow characteristics of valves subjected to various treatments to be easily determined. In practice, it was impossible to obtain a series of valves that were of equal size after fixation, so that the measured pressure differences had to be normalised suitably before the results from different valves could be directly compared.
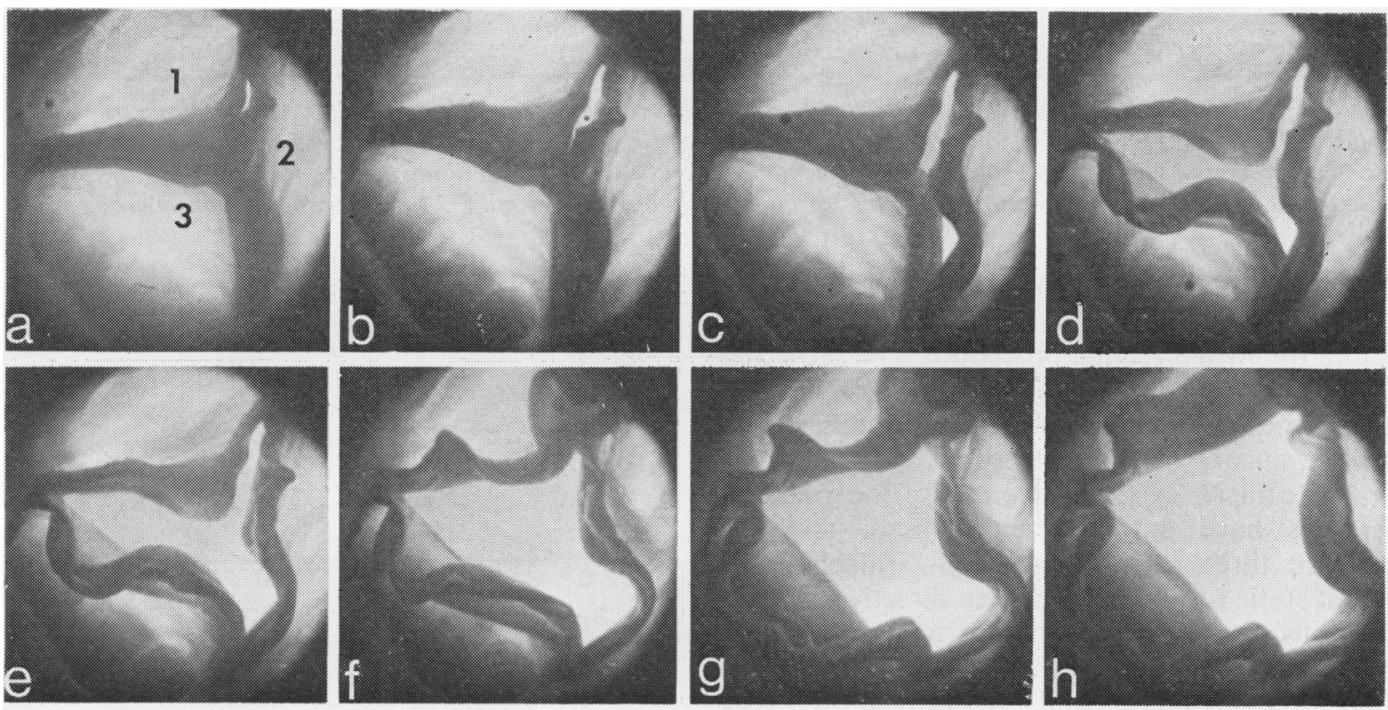

Fig 3 Axial views of $4 \mathrm{mmHg}$ valve for a range of steady forward flow rates in $\mathrm{l} / \mathrm{min}$ as follows: (a) $0 \cdot 0,($ b) $0 \cdot 3$, (c) $0 \cdot 6,(d) 1 \cdot 0,(e) 1 \cdot 8,(f) 3 \cdot 0,(g) 4 \cdot 4,(h) 5 \cdot 9$. Leaflet numbers are indicated in fig $3 a$. Leaflets 1 and 2 largely resisted opening until flow rate of $1.8 \mathrm{l} / \mathrm{min}(\mathrm{e})$ was reached and then opened progressively with increasing flow, $(f) \rightarrow(h)$. Leaflet 3 underwent a large movement at $1.0 \mathrm{l} / \mathrm{min}(d)$ and then progressively opened with increasing flow, $(e) \rightarrow(h)$.


Fig 4 Axial views of $4 \mathrm{mmHg}$ valve for steady forward flow rates in l/min as follows: (a) $0 \cdot 0,($ b) $1 \cdot 5$, (c) $2 \cdot 7$, (d) 8.2. Kink mode of leaflet movement also occurred at this fixation pressure. 

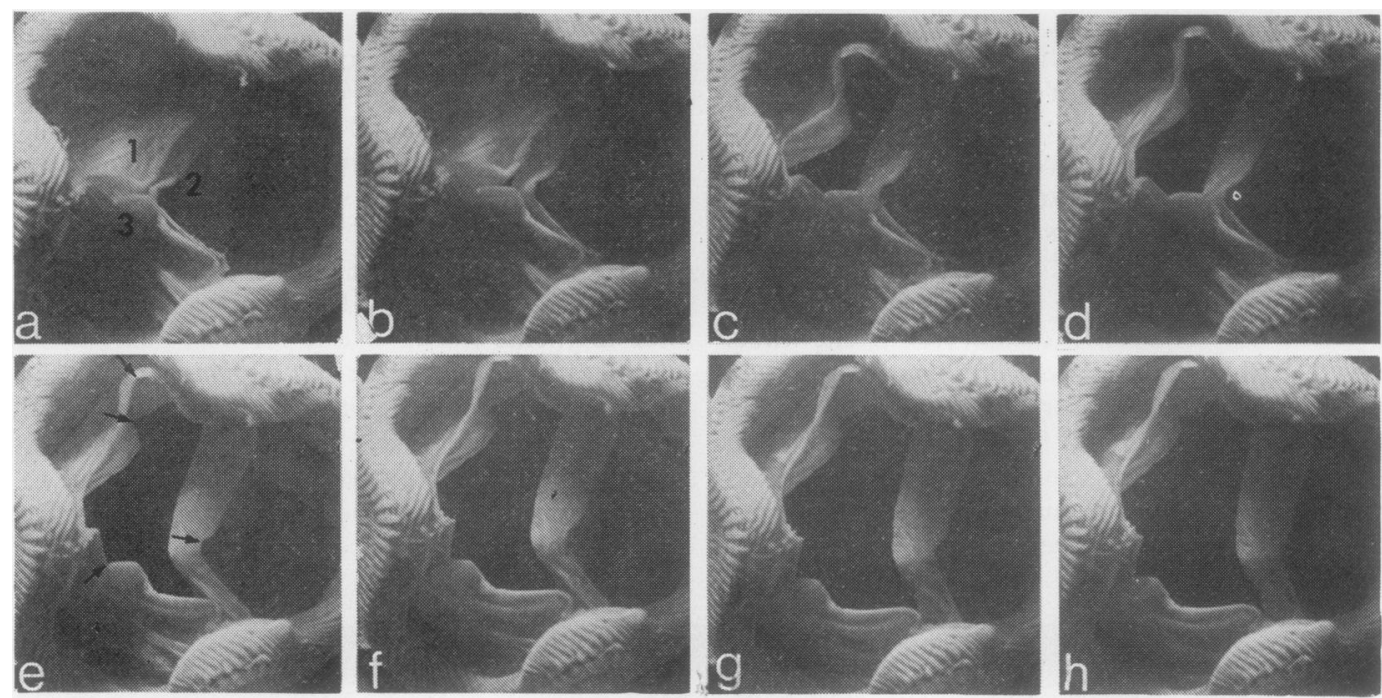

Fig 5 Axial views of Hancock valve (Ser No M31852) for a range of steady forward flow rates in l/min as follows: (a) $0 \cdot 0,(b) 0 \cdot 8,(c) 2 \cdot 4,(d) 3 \cdot 7,(e) 6 \cdot 5,(f) 8 \cdot 8,(g) 10 \cdot 5,(h) 11 \cdot 3$. Leaflet numbers are indicated in fig $5 a$. Leaflet 1 began to open at $2.4 \mathrm{l} / \mathrm{min}$ via kink mechanism. Leaflet 2 remained almost closed right through to maximum flow rate of $11 \cdot 3 \mathrm{l} / \mathrm{min}$, and leaflet 3 progressively opened beyond $5 \cdot 2 \mathrm{l} / \mathrm{min}$, again via kink mechanism.

A further problem occurred in measuring the internal cross-sectional area of the fully open valve required for such a scaling procedure. The projected orifice area obtained from an axial photograph of the valve may be a rather inaccurate estimate of the actual flow area, since the flow axis is not necessarily aligned with the camera axis. Consequently, the pressure differences have not been normalised, and the results for three valves fixed in glutaraldehyde at different static pressures are shown directly (fig 6).

Previous observations on valves not subjected to glutaraldehyde preservation have established that the leaflets are freely mobile and open fully at even very low flow rates (Thomson, 1976). A plot of the pressure drop, $\Delta \mathrm{p}$, against volume flow rate, $\mathrm{Q}$, for a typical untreated valve is included here (fig $6 a$ ) for comparison with the remaining graphs that pertain to glutaraldehyde-preserved valves.

Under the experimental conditions the relationship between $\Delta \mathrm{p}$ and $\mathrm{Q}$ is expected to be parabolic for a valve having a constant orifice area, and this ideal curve is shown by the continuous line in fig $6 \mathrm{a}$ using the experimental point at maximum flow rate as a reference. The shape of the experimental curve, shown by the broken line, confirmed that the untreated valve was virtually fully open for all flow rates.

The experimental pressure-flow curves for three glutaraldehyde-treated valves are shown in fig $6 \mathrm{~b}$, c, d. The characteristic feature was the rapid rise in pressure drop at very low flow rates that presumably
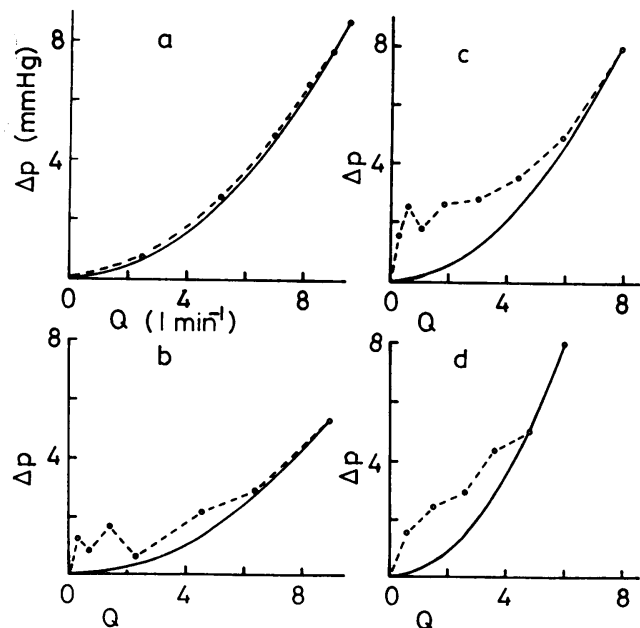

Fig 6 Pressure drop across a valve $(\triangle p)$ as a function of volume flow rate $(Q)$. Broken lines are experimental values obtained in Ringer's solution at $20^{\circ} \mathrm{C}$ with a flow rate increasing from zero. Continuous curve corresponds to an ideal valve of same orifice area that opens fully with a very low flow: (a) untreated valve (canine, of similar size), (b) $100 \mathrm{mmHg}$ valve, (c) $4 \mathrm{mmHg}$ valve, (d) " 0 " $\mathrm{mmHg}$ valve.

reflected the decreased leaflet compliance. In the case of valves treated at 100 and $4 \mathrm{mmHg}$ static pressure abrupt falls in pressure difference as the 
flow rate was increased were caused by the sudden hinge action of one leaflet, resulting in a considerable increase in valve orifice area. Earlier measurements of pressure-flow characteristics (Thomson, 1976) on the Hancock valve (fig 5) showed similar discontinuities in pressure related to the sudden opening of a leaflet. This behaviour was not evident in the case of the valve treated at " 0 " $\mathrm{mmHg}$ (fig $6 \mathrm{~d}$ ).

As before, the continuous lines are parabolas using the maximum flow datum point as a reference to indicate the expected behaviour of an ideal untreated valve of equivalent size. At high flow rates the experimental curves are close to the ideal indicating that each valve has reached its "fully open" position, although the shape of the orifice may be far from circular.

The pressure differences were measured as the volume flow rate was gradually increased from zero to a suitable maximum value. The glutaraldehydetreated valves exhibited hysteresis effects, so that the same curves do not apply to measurements made when the flow rate is decreasing.

\section{Indentation experiments}

Probe indentation results are shown for 100,4 , and " 0 " mmHg valves in fig $7 \mathrm{a}, \mathrm{b}$, c respectively. The indentations produced in the $100 \mathrm{mmHg}$ pressure valves comprised a series of radial and circumferential creases representing localised regions of high deformation separated by areas of undeformed tissue. In contrast the 4 and " 0 " $\mathrm{mmHg}$ treated valves exhibited smoothly rounded indentations reflecting a more even distribution of strain across the leaflets. Of these two valves, the $4 \mathrm{mmHg}$ valve tended to develop more localised regions of deformation with deep probing whereas the " 0 " $\mathrm{mmHg}$ valve retained its smooth indentation even with deep probing.
OPTICAL MICROSCOPY AND ASSOCIATED

STRESS/STRAIN BEHAVIOUR

\section{Crimp geometries}

In the leaflets examined from the $100 \mathrm{mmHg}$ valves the collagen at the coapting free edge was completely straight except for local sites where acute discontinuities had developed approximately at right angles to the free edge in towards the interior belly (fig 8a). These localised discontinuities in the otherwise straight array of collagen corresponded to the kinks formed during leaflet opening (fig 1c). The collagen in the belly of the leaflets was completely straight (fig 8b).

In contrast, the leaflets from the " 0 " $\mathrm{mmHg}$ valves showed a fully preserved crimp at both their free edge and belly (fig 9a,b). The $4 \mathrm{mmHg}$ valves showed an intermediate state as the free edge collagen contained a reduced crimp (fig 10a) and the belly collagen was either straight or nearly so (fig 10b).

All three leaflets from the single Hancock valve were examined for crimp geometries. The free edge collagen was straight except for localised discontinuities (fig 11a) similar to those observed in the high pressure treated valves. The belly collagen was straight (fig 11b).

\section{Stress/strain studies}

The $\sigma / \epsilon$ data confirmed quantitatively the influence of the collagen crimp on the mechanical properties of leaflets in the variously treated valves.

Representative $\sigma / \epsilon$ curves for tissue specimens removed from leaflets of both the high pressure valves and the single Hancock valve are presented (fig 12a). Both sets of tissue possessed less than $2 \%$ extensivity for the levels of loading investigated. Fig $12 \mathrm{~b}$ shows similar $\sigma / \epsilon$ data for 4 and " 0 " $\mathrm{mmHg}$ valves. Tissue from the " 0 " $\mathrm{mmHg}$ valves showed a


Fig 7 Probe indentation tests on convex ventricular surfaces of $100 \mathrm{mmHg}$ valve (photograph a), $4 \mathrm{mmHg}$ valve (b), and " $O$ " $\mathrm{mmHg}$ valve (c). 




well-defined "incubation" region where large extensions $(>10 \%)$ were produced with only small increases in stress. Tissue from the $4 \mathrm{mmHg}$ valves showed an intermediate $\sigma / \epsilon$ response in which the incubation region was either reduced significantly or eliminated.

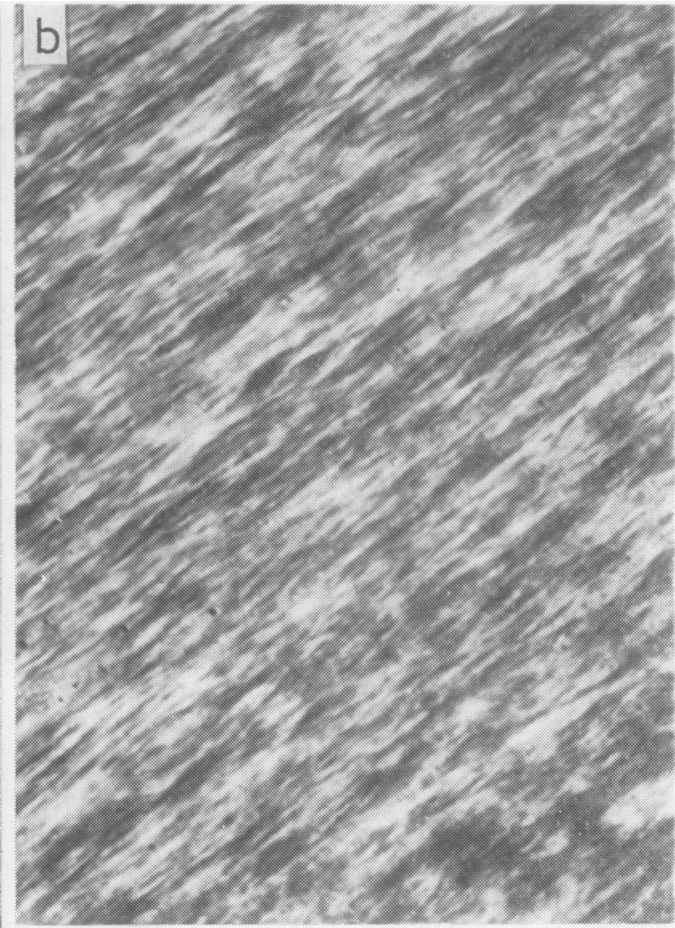

Fig 8 Nomarski micrographs of wet tissue showing appearance of collagen geometry in leaflet from $100 \mathrm{mmHg}$ valve: composite micrograph (a) - free edge showing kink sites (magnification $\times 100)$; micrograph $(b)$-interior belly $($ magnification $\times 500)$. 

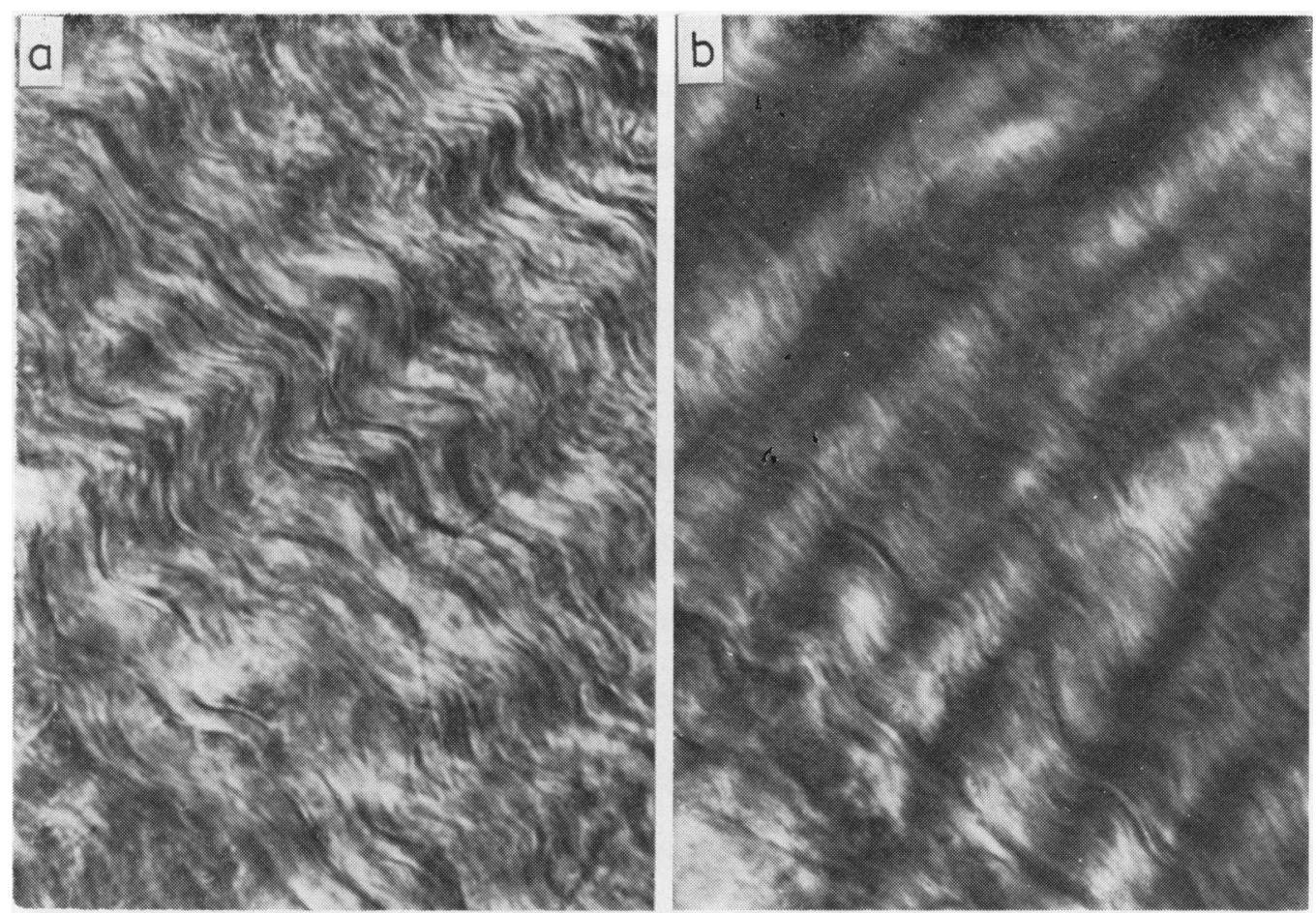

Fig 9 Nomarski micrographs of wet tissue showing appearance of collagen geometry in leaflet from " 0 " $\mathrm{mmHg}$ valve: micrograph (a)-free edge, micrograph $(b)$-interior belly (magnifications $\times 700$ ).
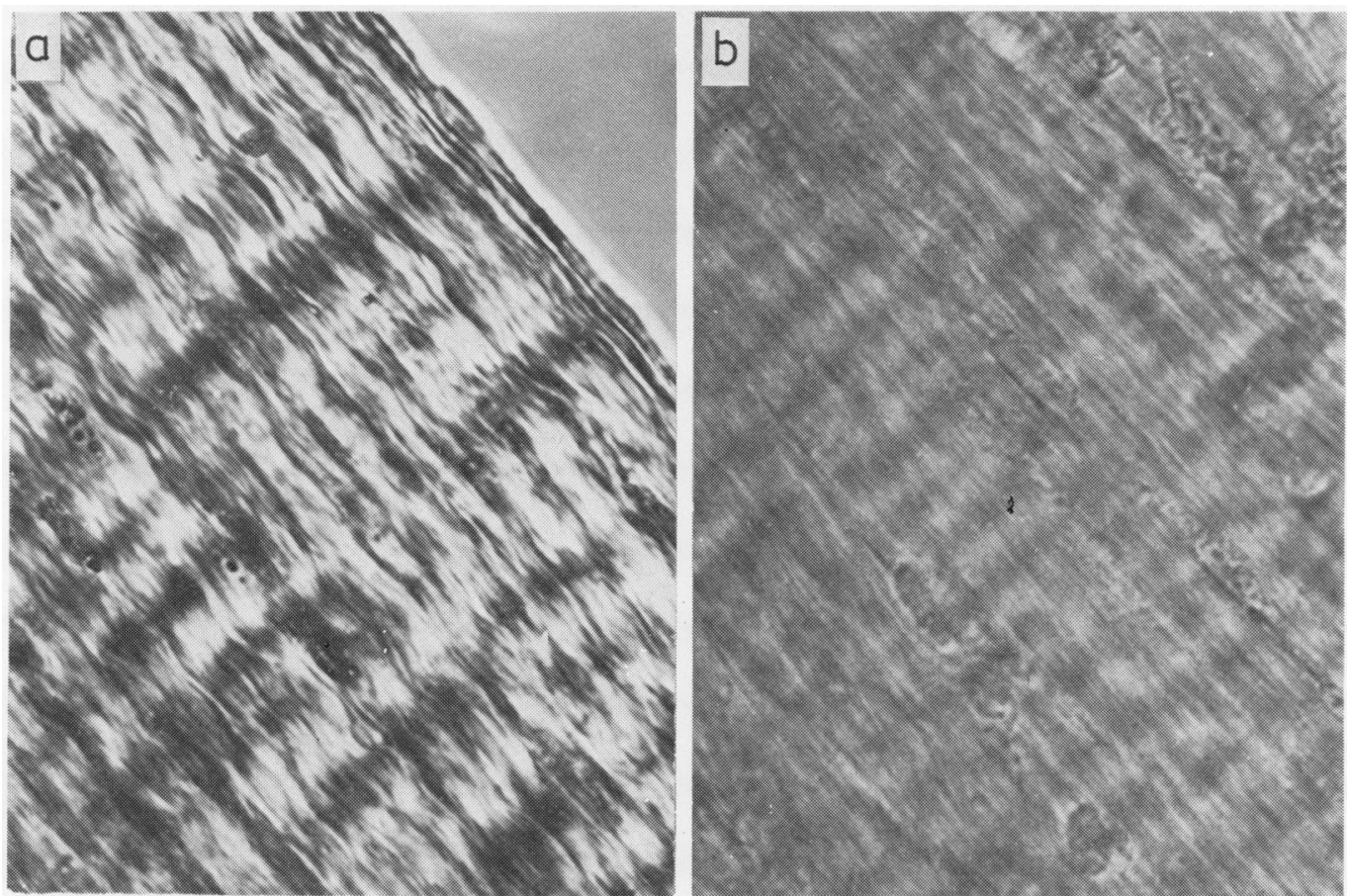

Fig 10 Nomarski micrographs of wet tissue showing appearance of collagen geometry in leaflet from $4 \mathrm{mmHg}$ valve: micrograph (a)-free edge, micrograph (b)—interior belly (magnifications $\times 700$ ). 


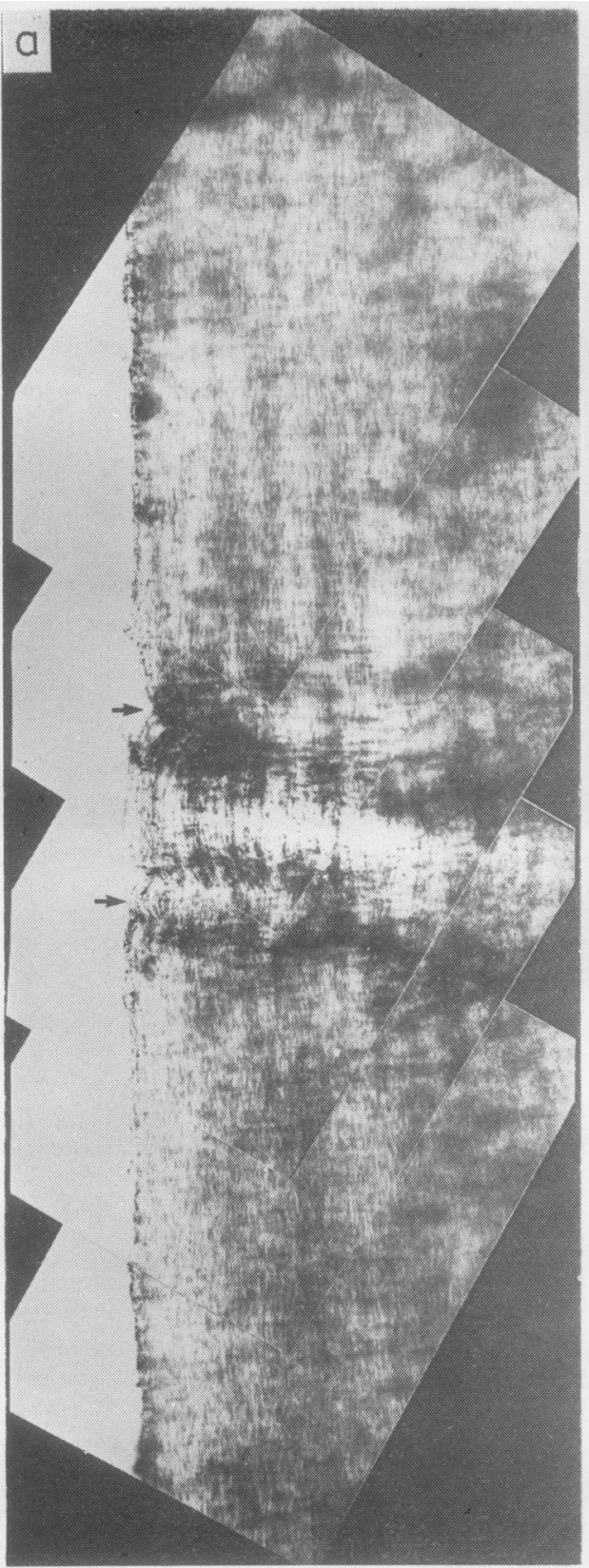

perties and consequently their opening characteristics under forward flow conditions.

Leaflets of valves treated at static pressures of $100 \mathrm{mmHg}$ opened sequentially and the pressureflow curves exhibited corresponding discontinuities. If such a valve was used where the maximum flow rate was less than that required to open the valve

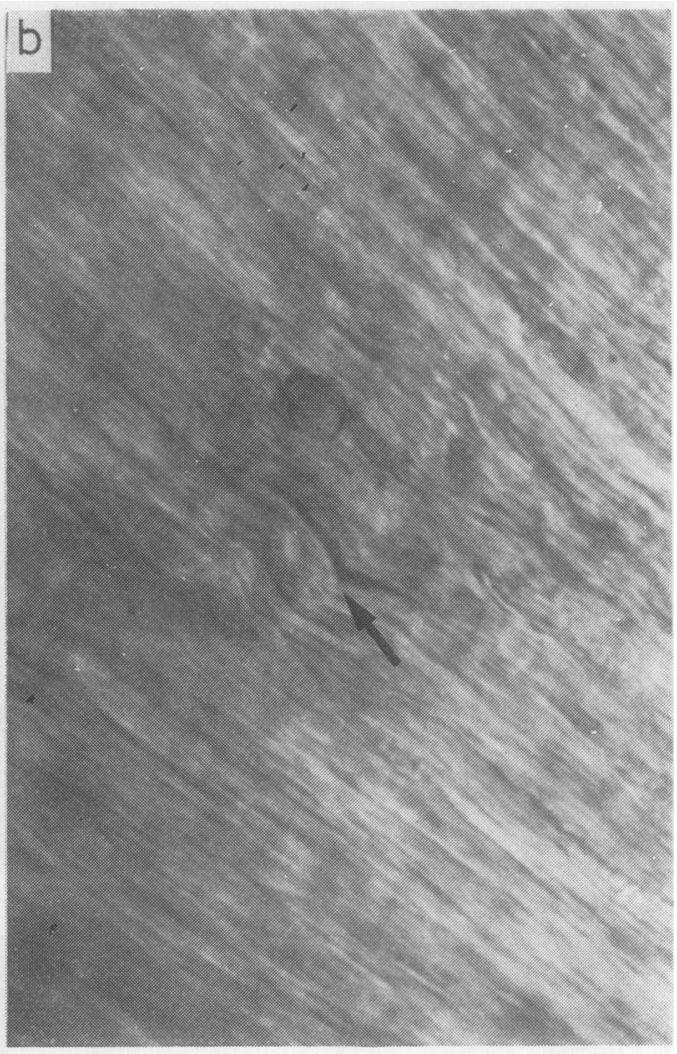

Fig 11 Nomarski micrographs of wet tissue showing appearance of collagen geometry in leaflet from Hancock valve: composite micrograph (a) - free edge showing kink sites (magnification $\times 120$ ), micrograph $(b)$-interior belly also exhibiting kinked region at site marked by arrow (magnification $\times 640$ ).

fully probably one leaflet could remain closed throughout the whole cycle. Hence the effective size of valve is considerably less than would be expected from the physical dimensions. To avoid such sequential opening, fixation at " 0 " pressure was required, since $4 \mathrm{mmHg}$ treated valves also tended to exhibit this sequential opening behaviour. 

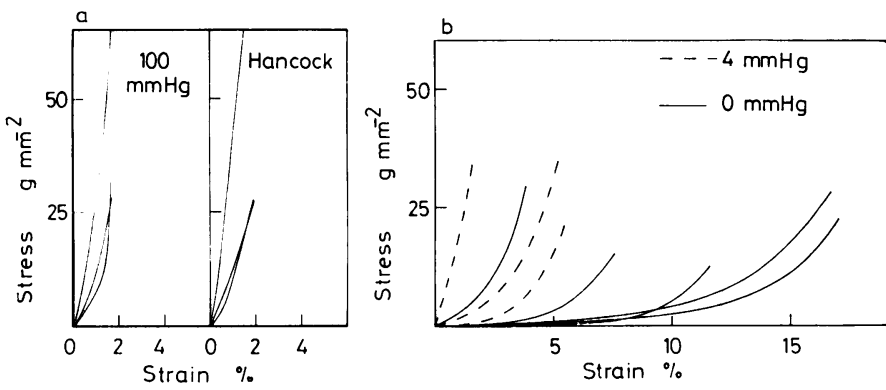

Fig 12(a) Representative o/ $\epsilon$ curves for tissue specimens removed from leaflets of $100 \mathrm{mmHg}$ valves and $\sigma / \epsilon$ curves for tissue specimens removed from all three leaflets of a single Hancock valve.

Fig 12(b) $\sigma / \epsilon$ curves for tissue specimens removed from leaflets of 4 and " 0 " $\mathrm{mmHg}$ valves. Varying degrees of initial strain shown particularly by "0" $\mathrm{mmHg}$ tissue simply reflect differing degrees of complexity of fibre organisation, thus adding more or less stiffness to crimped tissue.
All glutaraldehyde-treated valves produced higher pressure differences at lower flow rates than would be expected from untreated valves of equivalent sizes. Because of the difficulty experienced in scaling the effects of orifice area accurately, it is not possible to determine from these results whether the excess pressure difference over that for an ideal valve is a function of glutaraldehyde treatment pressure.

The preserved porcine heterograft valve has to be judged in terms of $(a)$ immediate haemodynamic function, and $(b)$ long-term life or fatigue endurance. The question therefore arises: Are there advantages to be gained from choosing a particular fixation pressure? The single Hancock valve examined was fixed in a manner that resulted in loss of the collagen crimp at both the free edge and the belly. Two additional Hancock valves that were examined after removal from patients and formalin fixation showed identical features, confirming that they were fixed under a positive head of pressure of glutaraldehyde that was sufficient to eliminate the acute crimp geometry of the collagen in its relaxed condition. These changes were similar to those observed at a fixation pressure of $100 \mathrm{mmHg}$.

The greatly increased elastic modulus of the tissue in the high pressure fixed valves means that there cannot be a graded response of the whole leaflet to the flow conditions. Instead, the leaflet tends to respond as a rigid elastic surface, resisting movement until the flow rate reaches such a level that local sites of highest stress suddenly yield to accommodate shape changes approximately compatible with the flow conditions. Hence the combination of sharp kinks and adjacent linear regions that characterised the free edges in the $100 \mathrm{mmHg}$ and Hancock valves. Similarly, when a sudden gross leaflet movement occurs this represents a localisation of strain usually near the margin of attachment at the aortic wall.

Such local regions of deformation in the tissue will consist of adjacent tension and compression strains much higher than the surrounding areas in the leaflet. The distribution of strain for a kink or hinge type region is shown schematically (fig 13b) and can be compared with the strain distribution associated with a graded response such as occurs in the " 0 " mmHg valves (fig 13a). ${ }^{1}$
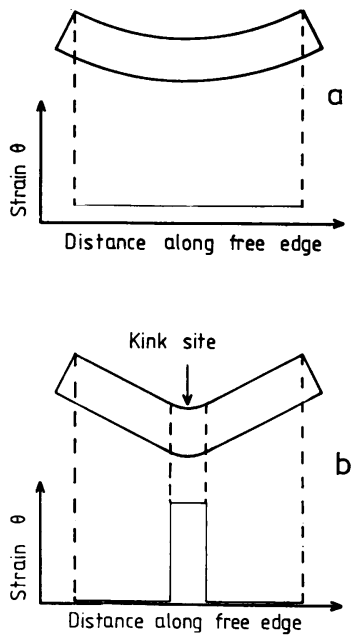

Fig 13 Distribution of strain (curvature $\theta$ ) along free edge of leaflets shown schematically for (a) tissue in which full crimp geometry is retained and (b) tissue in which crimp is removed with associated kink formation.

In direct relationship to this localisation of tensile and compressive strains in the tissue in which the collagen has suffered a permanent loss of crimp, Broom (1978a) has shown that glutaraldehydetreated porcine mitral tissue does suffer serious disruption after extended rapid cycling. Most significantly, it was shown that the process of disruption was confined to the regions of compressive flexure. Tensile loading even to levels far in excess of predicted maximum physiological levels

${ }^{1}$ The simple blunt probe indentation test described earlier provides an effective non-destructive means of assessing qualitatively the degree of collagen crimp retained in a glutaraldehyde-preserved valve before implantation. 
had no observable disruptive influence on the tissue structure.

Clearly then, the localised regions of deformation in the $100 \mathrm{mmHg}$ valves and in the Hancock valve where compressive deformation will occur, should be viewed as potential sites of tissue disruption. By retaining the full crimp geometry in the preserved tissue, the formation of these intense compression zones can be avoided and the mechanical life expectancy of the heterograft valve can be accordingly extended.

We are grateful for the encouragement given to this work by Brian G Barratt-Boyes, and in particular for his helpful comments during the preparation of this manuscript.

This research was supported by a grant from the Medical Research Council of New Zealand.

\section{References}

Albert, H M, Bryant, L R, and Schechter, F G (1977). Seven years experience with mounted porcine valves. Annals of Surgery, 185, 717-723.

Broom, N D (1977). The stress/strain and fatigue behaviour of glutaraldehyde-preserved heart-valve tissue. Journal of Biomechanics, 10, 707-724.

Broom, N D (1978a). Fatigue-induced damage in glutaraldehyde-preserved heart-valve tissue. Journal of Thoracic and Cardiovascular Surgery, 76, 202-211.
Broom, N D (1978b). Simultaneous morphological and stress-strain studies of the fibrous components in wet heart-valve leaflet tissue. Connective Tissue Research, 6 , 37-50.

Broom, N D (1978c). The observation of collagen and elastin structures in wet whole mounts of pulmonary and aortic leaflets. Journal of Thoracic and Cardiovascular Surgery, 75, 121-130.

Brown, J W, Dunn, J M, Spooner, E, and Kirsh, M M (1978). Late spontaneous disruption of a porcine xenograft mitral valve. Journal of Thoracic and Cardiovascular Surgery, 75, 606-611.

Rose, A G, Forman, R, and Bowen, R M (1978). Calcification of glutaraldehyde-fixed porcine xenograft. Thorax, 33, 111-114.

Stinson, E B, Griepp, R B, Oyer, P E, and Shumway, N E (1977). Long-term experience with porcine aortic valve xenografts. Journal of Thoracic and Cardiovascular Surgery, 73, 54-63.

Thomson, F J (1976). Progress report on the development of a flexible stent for heart-valve homografts, Report No $132 \mathrm{M76/5}$. School of Engineering, University of Auckland, New Zealand.

Thomson, F J, and Barratt-Boyes, B G (1977). The glutaraldehyde-treated heterograft valve-some engineering observations. Journal of Thoracic and Cardiovascular Surgery, 74, 317-321.

Requests for reprints to: Dr N D Broom, Department of Mechanical Engineering, University of Auckland, Auckland. 